\title{
Effectiveness of 'Mother Supportive Group' intervention on childhood nutrition improvement in Monaragala District of Sri Lanka
}

\author{
Nimal Gamagedara ${ }^{1,2^{*}}$, Eresha Mendis ${ }^{1}$, Nihal Wijesinghe ${ }^{1}$ \\ ${ }^{1}$ Postgraduate Institute of Agriculture, University of Peradeniya, Sri Lanka; ${ }^{2}$ Department of Health Services, \\ Uva Province, Sri Lanka
}

*Correspondence: nimals74@gmail.com

(Dhttps://orcid.org/0000-0002-0339-0724

DOI: https://doi.org/10.4038/jccpsl.v25i4.8223

Received on 30 August 2019

Accepted on 16 November 2019

\begin{abstract}
Introduction: Effective, largescale, and nutrition-sensitive interventions addressing underlying determinants are required to accelerate progress in under-five nutrition.

Objectives: To determine the effective coverage of Mother Supportive Group (MSG) intervention among its primary target population and its effectiveness in promotion of nutrition and growth of under-five children

Methods: A descriptive, cross-sectional study was carried out among under-five children of Monaragala District. The study population was categorized into 'MSG' if the child was registered with intervention and into 'NonMSG' if it was not. MSGs were defined as effective, if MSG meetings were held once a month consecutively over the past six months with a meeting report for each meeting held. A sample of 1140 children (570 from each 'MSG' and 'Non-MSG' groups) was selected by systematic random sampling method. Weight and height of children were measured with appropriate instruments. Other information was collected by an interviewer administered questionnaire.
\end{abstract}

Results: Effective coverage of primary target population by MSG intervention was 2.6\% and it was not uniformly implemented in the community. Only one medical officer of health (MOH) area reported effective coverage of 25\%, while it was $10-15 \%$ in five $\mathrm{MOH}$ areas and less than $1 \%$ in two $\mathrm{MOH}$ areas. Attending Growth Monitoring and Promotion Programme in more than the recommended frequency was significantly higher (77.5\%) in MSG (Non-MSG=49.7\%). Fathers' smoking was significantly high (54\%) in MSGs (Non-MSG=46\%). Feeding on solid food during illness has significantly improved with MSG intervention (MSG=20.7\% versus Non-MSG=11.9\%). None of the other practices and selected behaviours showed significant improvement with MSGs. No significant difference in the prevalence of underweight, stunting and wasting was detected between MSG and Non-MSG groups.

Conclusions: Effective coverage of MSG intervention was significantly low while its implementation was not uniform in the community. MSG intervention was not effective enough at its present level of implementation, to show significant nutrition and growth promotion among children of the under-five category. It is recommended to revisit the MSG intervention before further implementation.

Key words: effectiveness, evaluation, nutrition, under-five children, health promotion 


\section{Introduction}

Nutrition is the science of food and it has a direct relationship to the health of a human being. The nutritional requirements vary in pregnancy, infancy and childhood, adolescence, the elderly, during diseases and recovery from diseases, and during disasters. In 2011 , it was estimated that $26 \%, 16 \%$ and $8 \%$ of under-five children in the world were stunted, underweight and wasted, respectively (1). Furthermore, 26\% of world's stunted under-five children and $70 \%$ of under-five children with wasting live in Asia (2). In Sri Lanka, the prevalence of stunting, underweight and wasting in the same year were $17.3 \%, 15.1 \%$ and $20.5 \%$ respectively, while the corresponding indicators were 15.9\%, 25.4\% and 24.2\% in Monaragala District (3). Worldwide, over 10 million children under the age of five years die every year from preventable and treatable illnesses despite effective health interventions. At least half of these deaths are caused by undernutrition (4). It is further estimated that there are 2.8 million child deaths ( $28 \%$ of under-five deaths) and 114 million disability-adjusted life years (DALYs) (27\% of underfive DALYs) attributable to childhood undernutrition, while it constitutes $8.5 \%$ of the total global disease burden (5).

There are many programmes being implemented by the government of Sri Lanka, focusing on the growth and development of children less than five years of age. Supplementary and therapeutic food distribution programmes for under-five children, pregnant mothers and lactating mothers; micronutrient supplementation and fortification programmes; capacity building on Infant and Young Child Feeding Practices (IYCF) and programmes to improve nutrition knowledge for public health staff; Growth Monitoring and Promotion (GMP) Programme; and community mobilization programmes towards strengthening the existing public health interventions as well as addressing root causes of under-five undernutrition related to food insecurity are some of the major interventions presently being implemented. Mother Supportive Group (MSG) intervention was one of the two community mobilization interventions that the public health system of Sri Lanka has incorporated into health and nutrition promotion especially among children under-five. The older intervention was the 'Health Volunteer System' which did not have the element of empowerment and was merely for assisting primary healthcare staff to carry out routine tasks at maternal and child health clinics. One of the main objectives of MSG intervention was to improve the nutrition of children under-five by promoting healthy behaviours and improving care practices for a child under-five through community empowerment.

Proper evaluation is an essential component of project and programme management to determine the effectiveness of an intervention in achieving its intended results. For example, Somassé et al (6) reported that handover conditions and scaling-up requirements were unsatisfactory even though the package of communitybased management of acute malnutrition was effective in terms of reducing under-five malnutrition in Burkina Faso. Poor integration into health system, lack of resources and insufficient advocacy were identified as contributory factors for handover conditions and scaling-up requirements being unsatisfactory. However, another study from Iran showed a reduction in the incidence of under-five undernutrition from $6.5 \%$ to $1.8 \%$ within a year of implementing a community-based nutritional intervention, which comprised practical instructions on feeding methods, de-worming, environmental sanitation, promotion of home-grown vegetables and reinforcement of growth monitoring programme (7). A formative review of MSGs in Northern and Eastern Provinces conducted in 2015 by the Ministry of Health, Sri Lanka in collaboration with UNICEF and Australian Aid found that messages imparted on nutrition and health were very broad while food demonstration sessions carried out were similar to what the World Vision Lanka Organization had implemented under their Positive Deviance/Health Nutrition Programme. Furthermore, the training carried out by the public health midwives (PHMs) was limited to the office bearers of MSGs and not extended in turn to their respective MSG members. Consequently, the health messages delivered were not uniform and in-depth, while some of the MSG members were not aware why certain messages were delivered or some activities were performed by PHMs. It was further revealed that the mandate of MSGs was more towards service provision than on problem analysis, participatory development and empowerment. The same study has further emphasized that record keeping, maintaining lists of target beneficiaries and rates of undernutrition together with progress of nutritional status among the target group and follow up activities were not up to the standard (8).

It is now more than six years since MSG intervention has been implemented in the community. 
A proper evaluation of this intervention has not yet been attempted except a formative review conducted in Northern and Eastern Provinces in 2015; and regional as well as national annual reviews being conducted by the Health Promotion Bureau (HPB) where only qualitative assessments were carried out. Furthermore, only the process and output indicators have been looked into during these reviews. Therefore, having scientific evidence on effectiveness of this intervention in terms of reducing childhood undernutrition may help to improve and extend it further in the community.

\section{Methods}

A descriptive cross-sectional study was conducted from March to June 2018 among children under-five years who were permanently living in the district of Monaragala. Monaragala is the second largest district in Sri Lanka and one of the two districts of Uva Province. In 2018, its mid-year population was 485,812 (9) and there were 11 medical officers of health (MOH) areas and 206 PHM areas in the district. Twenty-four PHM areas were vacant at the time of the study. There were 46,216 children less than five years of age in the district, of whom 40,794 (88\%) were living in PHM areas occupied by a permanent PHM at least for one year by 2018 (10).

Firstly, 40,794 children were categorized into two groups, namely 'MSG' and 'Non-MSG'. A child was categorized into 'MSG' group if the child was registered with the MSG intervention; and into 'nonMSG' if it was not. MSGs were further categorized into 'effectively functioning MSG' and 'ineffectively functioning MSG'. An MSG was defined as 'effective' if the MSG had its meetings consecutively once a month during immediate past six months and if there was a meeting report for each meeting held; and as 'ineffective' if it was not. The study participants who were not yet registered in an MSG were categorized as Non-MSG.

Sample size was determined by an appropriate formula (11) and it was 1,140 children, with 570 children in each 'MSG' and 'non-MSG' categories. A list of all under-five children was prepared for the entire district having collected the name of the child, name of the mother/father/guardian and status of engagement in MSGs from each non-vacant PHM area. A separate list for 'MSG' and 'non-MSG' was prepared in alphabetical order of their names and study participants of each category were then selected by applying systematic random sampling method. Data collection was performed by trained data collectors who were General Certificate of Education Advance Level (GCE A/L) qualified. Principal researcher supervised the entire data collection process. Weight and height/length of selected children were measured using standard appropriate instruments. Other information on sociodemographic characteristics, behavioural factors and feeding practices were collected by a pre-tested and validated interviewer-administered questionnaire.

\section{Data analysis}

Data were analysed using the Statistical Package for Social Sciences (SPSS) version 21.0. Crude odds ratio (OR) with 95\% confidence interval (CI) and $\mathrm{p}$ values were performed to determine statistical associations of selected variables with MSG intervention at univariate analysis. Only the variables significant at univariate analysis were considered for multivariate analysis to calculate adjusted OR. Age-specific prevalence of undernutrition among selected children was calculated using WHO Anthro 2005 Software.

\section{Results}

Out of 40,794 under-five children who were living in the selected PHM areas 3,743 (9.2\%) children were registered for MSG intervention by 2018, giving a gross coverage of the primary target population for MSG intervention of 9.2\%. Of them, 1,085 (28.9\%) actively participated in the intervention, giving an effective coverage of $2.6 \%$. Furthermore, implementation of the MSG intervention was not uniform over $11 \mathrm{MOH}$ areas. The highest effective coverage (24.8\%) was reported from Madulla MOH Area, while it was not effectively implemented in Wellawaya and Sewanagala MOH Areas.

In univariate analysis, among behavioural factors related to promotion of nutrition and growth, and feeding practices, smoking by father of the child was significantly higher (54\%) in the MSG group compared to $46 \%$ in the Non-MSG group (crude OR=1.29; 95\% CI=1.02, 1.63) (Table 1). Attending GMP was marginally higher (87.0\%) among children under two years of age in the MSG group compared to non-MSG group (85.4\%). This association was not statistically significant (crude OR=1.44; 95\% CI=0.64, 2.03). In further analysis, among the children who were more than two years of age and not having growth faltering, 
a significantly higher proportion (77.5\%) of children between 2-5 years of age from MSG group attended GMP in excess of the recommended frequency during previous six months, while it was lower (49.7\%) among the non-MSG group (crude OR=3.49; 95\% $\mathrm{CI}=2.52$, 4.84) (Table 1).

With regards to feeding practices, exclusive breastfeeding at six months of age was higher (89.7\%) among children of the MSG group in comparison to those of non-MSG group (85.1\%). However, it was not statistically significant (crude OR=1.53; 95\%
$\mathrm{CI}=0.78$, 3.01). A significantly higher proportion of children in the MSG group (20.7\%) was fed satisfactorily with solid food during illness compared to only $11.9 \%$ of children in non-MSG group (crude $\mathrm{OR}=1.93$; 95\% $\mathrm{CI}=1.2$, 3.09). None of the other feeding practices considered were significantly associated with MSG intervention (Table 2). The variables that showed significant association at univariate analysis were subjected to multiple logistic regression analysis, during which only three variables were associated significantly with the MSG group (Table 3).

\section{Table 1. Association between behavioural factors and MSG intervention in study population}

\begin{tabular}{|c|c|c|c|}
\hline \multirow[t]{2}{*}{ Characteristic } & \multicolumn{2}{|c|}{ No. (\%) } & \multirow{2}{*}{$\begin{array}{l}\text { Crude OR } \\
(95 \% \mathrm{CI})\end{array}$} \\
\hline & Yes & No & \\
\hline \multicolumn{4}{|c|}{ Disposing child's faeces sanitarily } \\
\hline MSG & $487(89.9)$ & $55(10.1)$ & 1.06 \\
\hline Non-MSG & $461(89.3)$ & $55(10.7)$ & $(0.71,1.57)$ \\
\hline \multicolumn{4}{|c|}{ Hand washing by mother before preparing child's meal } \\
\hline MSG & $287(84.2)$ & $54(15.8)$ & 0.8 \\
\hline Non-MSG & $291(86.9)$ & $44(13.1)$ & $(0.52,1.24)$ \\
\hline \multicolumn{4}{|c|}{ Hand washing by mother after the toilet } \\
\hline MSG & $491(96.7)$ & $17(3.8)$ & 0.78 \\
\hline Non-MSG & $484(97.4)$ & $13(2.6)$ & $(0.37,1.62)$ \\
\hline \multicolumn{4}{|c|}{ Hand washing by mother after cleaning child } \\
\hline MSG & $475(96.2)$ & $19(3.8)$ & 1.44 \\
\hline Non-MSG & $453(94.6)$ & $26(5.4)$ & $(0.78,2.63)$ \\
\hline \multicolumn{4}{|c|}{ Smoking by father of the child } \\
\hline MSG & $279(54.1)$ & $280(47.8)$ & 1.29 \\
\hline Non-MSG & $237(45.9)$ & $306(52.2)$ & $(1.02,1.63)$ \\
\hline \multicolumn{4}{|c|}{ Washed child's hands by mother before meal } \\
\hline MSG & $416(88.9)$ & $52(11.1)$ & 0.8 \\
\hline Non-MSG & $392(91.0)$ & $39(9.0)$ & $(0.51,1.23)$ \\
\hline
\end{tabular}


Washed child's hands after toilet
MSG
$67(95.7)$
$3(4.3)$
0.96
Non-MSG
$80(100.0)$
$0(0.0)$
$(0.91,1.01)$

\section{Consumed alcohol by father}

$\begin{array}{llrr}\text { MSG } & 412(73.7) & 147(26.3) & 1.22 \\ \text { Non-MSG } & 379(69.7) & 165(30.3) & (0.94,1.59)\end{array}$

Chewed betel by father

$\begin{array}{lllr}\text { MSG } & 349(62.4) & 210(37.6) & 1.05 \\ \text { Non-MSG } & 333(61.2) & 211(38.8) & (0.83,1.34)\end{array}$

Chewed betel by mother

$\begin{array}{lrrr}\text { MSG } & 103(18.5) & 456(83.5) & 1.33 \\ \text { Non-MSG } & 79(14.5) & 465(85.5) & (0.97,1.83)\end{array}$

Children $<2$ yrs attended satisfactorily

$\begin{array}{lllr}\text { MSG } & 160(87.0) & 24(13.0) & 1.14 \\ \text { Non-MSG } & 176(85.4) & 30(14.6) & (0.64,2.03)\end{array}$

Children $\geq 2$ yrs attended GMP more than recommended

$\begin{array}{lrrr}\text { MSG } & 283(77.5) & 82(22.5) & 3.49 \\ \text { Non-MSG } & 164(49.7) & 166(50.3) & (2.52,4.84)\end{array}$

MSG=Mother Support Group; CI=confidence interval; OR=odds ratio; GMP=growth monitoring and promotion

Table 2. Association between feeding practices and MSG intervention in study population

\begin{tabular}{|c|c|c|c|}
\hline \multirow[t]{2}{*}{ Characteristic } & \multicolumn{2}{|c|}{ No. $(\%)$} & \multirow{2}{*}{$\begin{array}{l}\text { Crude OR } \\
(95 \% \mathrm{CI})\end{array}$} \\
\hline & Yes & No & \\
\hline \multicolumn{4}{|c|}{ Initiation of breastfeeding within $1^{\text {st }}$ hour of birth } \\
\hline MSG & $160(94.7)$ & $9(5.3)$ & 1.09 \\
\hline Non-MSG & $180(94.2)$ & $11(5.8)$ & $(0.44,2.69)$ \\
\hline \multicolumn{4}{|c|}{ Colostrum given to child without discarding } \\
\hline MSG & $158(95.8)$ & $7(4.2)$ & 0.36 \\
\hline Non-MSG & $189(98.4)$ & $3(1.6)$ & $(0.09,1.41)$ \\
\hline \multicolumn{4}{|c|}{ Not giving anything within 4 months of child's age } \\
\hline MSG & $5(3.1)$ & $158(96.9)$ & 0.96 \\
\hline Non-MSG & $6(3.2)$ & $182(96.8)$ & $(0.29,3.21)$ \\
\hline
\end{tabular}


Exclusive breastfeeding at 6 months of child's age

MSG

Non-MSG

Continued breastfeeding at $1^{\text {st }}$ year of child's age

$\begin{array}{lllr}\text { MSG } & 40(95.2) & 2(4.8) & 1.05 \\ \text { Non-MSG } & 38(95.0) & 2(5.0) & (0.14,7.85)\end{array}$

\section{Starting complementary feeding with an appropriate food}

$\begin{array}{lllr}\text { MSG } & 15(65.2) & 8(34.8) & 0.7 \\ \text { Non-MSG } & 24(72.7) & 9(27.3) & (0.22,2.22)\end{array}$

Breastfeeding during illness being satisfactory

$\begin{array}{lllr}\text { MSG } & 57(30.2) & 132(69.8) & 1.1 \\ \text { Non-MSG } & 48(28.2) & 122(71.8) & (0.7,1.73)\end{array}$

Feeding with liquid diet during illness being satisfactory

$\begin{array}{lllr}\text { MSG } & 93(32.9) & 190(67.1) & 1.3 \\ \text { Non-MSG } & 64(27.4) & 170(72.6) & (0.89,1.9)\end{array}$

Feeding with solid food during illness being satisfactory

$\begin{array}{lllr}\text { MSG } & 60(20.7) & 230(79.3) & 1.93 \\ \text { Non-MSG } & 31(11.9) & 229(88.1) & (1.2,3.09)\end{array}$

\section{Having minimum dietary diversity}

$\begin{array}{lllr}\text { MSG } & 138(86.8) & 21(13.2) & 0.77 \\ \text { Non-MSG } & 145(89.5) & 17(10.5) & (0.39,1.52)\end{array}$

\section{Having minimum acceptable diet}

$\begin{array}{lllr}\text { MSG } & 138(86.8) & 21(13.2) & 0.82 \\ \text { Non-MSG } & 144(88.9) & 18(11.1) & (0.42,1.61)\end{array}$

\section{Giving iron rich diet to child}

$\begin{array}{lllr}\text { MSG } & 136(85.0) & 24(15.0) & 0.75 \\ \text { Non-MSG } & 143(88.3) & 19(11.7) & (0.4,1.44)\end{array}$

MSG=Mother Support Group; OR=odds ratio; $\mathrm{CI}=$ confidence interval

The prevalence of underweight, wasting and stunting among children of MSG group were 23.8\% (95\% CI=19.5\%, 26.5\%), 20.0\% (95\% CI=16.7\%, $23.3 \%)$ and $13.9 \%$ (95\% CI=11.1\%, 16.9\%) while those of non-MSG group were $22.1 \%$ (95\% CI=18.5\%,
25.5\%), $16.7 \%$ (95\% CI=13.8\%, 20.2\%) and 15.2 (95\% CI=11.9\%, 18.1\%), respectively. Observed difference between MSG and non-MSG groups of underweight $(\mathrm{p}=0.51)$, wasting $(\mathrm{p}=0.14)$ and stunting $(p=0.52)$ were not statistically significant (Table 4). 
Table 3. Adjusted odds ratios for associated behavioural and feeding factors of MSG intervention

\begin{tabular}{|c|c|c|c|}
\hline \multirow[t]{2}{*}{ Characteristic } & \multicolumn{2}{|c|}{ No. $(\%)$} & \multirow{2}{*}{$\begin{array}{l}\text { Adjusted OR } \\
\qquad(95 \% \text { CI })\end{array}$} \\
\hline & Yes & No & \\
\hline \multicolumn{4}{|c|}{ Children $\geq 2$ years attended GMP more than recommended } \\
\hline MSG & $283(77.5)$ & $82(22.5)$ & 3.95 \\
\hline Non-MSG & $164(49.7)$ & $166(50.3)$ & $(2.44,6.34)$ \\
\hline \multicolumn{4}{|c|}{ Feeding with solid food during illness being satisfactory } \\
\hline MSG & $60(20.7)$ & $230(79.3)$ & 2.13 \\
\hline Non-MSG & $31(11.9)$ & $229(88.1)$ & $(1.16,3.91)$ \\
\hline \multicolumn{4}{|c|}{ Smoking by father of the child } \\
\hline MSG & $279(54.1)$ & $280(47.8)$ & 1.72 \\
\hline Non-MSG & $237(45.9)$ & $306(52.2)$ & $(1.1,2.7)$ \\
\hline \multicolumn{4}{|c|}{ Consumed alcohol by father } \\
\hline MSG & $412(73.7)$ & $147(26.3)$ & 0.7 \\
\hline Non-MSG & $379(69.7)$ & $165(30.3)$ & $(0.39,1.26)$ \\
\hline \multicolumn{4}{|c|}{ Chewed betel by mother } \\
\hline MSG & $103(18.5)$ & $456(83.5)$ & 1.1 \\
\hline Non-MSG & $79(14.5)$ & $465(85.5)$ & $(0.6,2.02)$ \\
\hline
\end{tabular}

MSG=Mother Support Group; OR=odds ratio; $\mathrm{CI}=$ confidence interval; GMP=growth monitoring and promotion

Table 4. Distribution of the nutritional status of children by MSG intervention in study population

\begin{tabular}{|c|c|c|c|c|c|c|}
\hline Category & No. (\%) & Total & $\mathrm{SE}$ & Width & $95 \%$ CI & p value \\
\hline \multicolumn{7}{|c|}{ Underweight } \\
\hline MSG & $131(0.24)$ & $551^{\mathrm{a}}$ & 0.018 & 0.035 & $(0.195,0.265)$ & \\
\hline Non-MSG & $118(0.22)$ & $534^{\mathrm{b}}$ & 0.018 & 0.035 & $(0.185,0.255)$ & 0.511 \\
\hline \multicolumn{7}{|l|}{ Wasting } \\
\hline MSG & $111(0.2)$ & $554^{c}$ & 0.017 & 0.033 & $(0.167,0.233)$ & \\
\hline Non-MSG & $90(0.17)$ & $542^{\mathrm{d}}$ & 0.016 & 0.032 & $(0.138,0.202)$ & 0.142 \\
\hline \multicolumn{7}{|l|}{ Stunting } \\
\hline MSG & $75(0.14)$ & $541^{\mathrm{e}}$ & 0.015 & 0.029 & $(0.111,0.169)$ & \\
\hline Non-MSG & $80(0.15)$ & $525^{f}$ & 0.156 & 0.031 & $(0.119,0.181)$ & 0.524 \\
\hline
\end{tabular}

MSG=Mother Support Group; Missing values: ${ }^{\mathrm{a}}=19,{ }^{\mathrm{b}}=36,{ }^{\mathrm{c}}=16, \stackrel{\mathrm{d}}{=}=28, \stackrel{\mathrm{e}}{=}=29, \stackrel{\mathrm{f}}{=}=45$; SE$=$ standard error; $\mathrm{CI}=$ confidence interval 


\section{Discussion}

According to the findings of this study, gross coverage of the primary target population was $9.2 \%$ and its effective coverage was $2.6 \%$ after a significant period (six years) following the implementation of MSG intervention in the community. Further, the intervention was not uniformly implemented over $11 \mathrm{MOH}$ areas in the district. For example, only Medulla MOH Area had $25 \%$ effective coverage, while five $\mathrm{MOH}$ areas reported $10-15 \%$ effective coverage and two $\mathrm{MOH}$ areas less than $1 \%$. In Monaragala District, though prevalence of stunting has decreased by 5.8\% from 2006 (21.7\%) to 2016 (15.9\%), the prevalence of underweight has decreased only by 2.4\% from 2006 (26.6\%) to 2016 (24.2\%) and wasting increased by 5.6\% from 2006 (19.8\%) to $2016(25.4 \%)(3,10)$. A systematic review (12) has shown that a higher level of implementation of public health interventions is often associated with better outcomes. Prevalence of stunting, wasting and underweight are considered as outcome indicators of nutritional interventions such as MSG. Therefore, the effective coverage being $2.6 \%$ does not seem sufficient to make a substantial change in district figures of underfive under nutrition during last six years of its implementation.

Feeding practices and behavioural factors, which are directly or indirectly related to under-five nutrition were expected to be promoted with MSG intervention in the community. On the contrary, in this study, smoking by father and attending GMP centres by children aged two or more were significantly but negatively associated with MSG intervention at regression analysis. Generally, it is mothers who are most often accompanying their children to GMP centres and therefore more conscious about growth monitoring and promotion of their children. Accordingly, mothers of MSG intervention may have revealed more about smoking status of father of the child with the intention of preventing it, while mothers of non-MSG group may have relatively under-reported. Therefore, observed increased smoking by fathers with MSG intervention could have resulted from information bias. At the same time, parents may have become more conscious about adverse nutritional outcome such as underweight without complete information about under nutrition especially during various activities of MSG intervention compared to those in non-MSG group. Therefore, parents of MSG intervention may have attended GMP more frequently than required with the intention of preventing adverse nutritional outcomes among their children. Attending GMP centres in excess of the recommended frequency will negatively affect the quality of care provided in a GMP centre which may again adversely affect the nutrition and growth promotion of under-five children in the community.

Among the feeding practices considered in this study, only feeding with appropriate solid food during illness was significantly associated with MSG intervention in regression analysis. Feeding practices have been given more priority in growth monitoring and promotion by both public health staff in their routine $\mathrm{MCH}$ programme and parents irrespective of the intervention. This may have resulted in no association observed for most of the feeding practices with MSG intervention considered in our study. There was room for improvement in the community as far as population figures of exclusive breastfeeding at six months and feeding during illness were considered. For example, exclusive breastfeeding rate reported in DHS 2016 was $82 \%$ (feeding during illness was not reported). Mothers receive health messages on breastfeeding and complementary feeding continuously during antenatal period as well as during infancy through routine $\mathrm{MCH}$ programme of the country irrespective of the MSG intervention. Mothers give priority to such messages at least during early childhood period, and therefore a significant improvement in these feeding practices with MSG intervention could not be observed.

Both behavioural factors and feeding practices are very important in nutrition as well as growth promotion among children less than five years of age. In this study, it did not reveal any significant changes in most of the behavioural factors as well as feeding practices among children and their parents of the intervention group compared to non-intervention group. Furthermore, some of the behavioural factors which are important in nutrition promotion were negatively associated with the intervention. This has resulted in no change in the nutrition outcomes among underfive children of MSG group in terms of underweight, wasting and stunting. Studies by Malekafzali et al and Somassé et al (6-7) have shown the importance of post evaluation of an intervention for decision making on its further implementation in a community to achieve desired objectives. In Iran, a post-evaluation study showed how a community based nutritional intervention be effective in improving under-five 
nutrition as their intervention could achieve reduction of under nutrition among under-five children from $6.5 \%$ to $1.8 \%$ within a year of implementing the intervention. The intervention being effective alone is not enough to solve a community health problem such as under-five under nutrition. The intervention also needs to be sustainable in a given community with an effective coverage. Somassé et al (6) reported that their community-based management of acute malnutrition was effective in terms of reducing under-five malnutrition in Burkina Faso as they could achieve $90 \%$ coverage of the target population within three years of its implementation. Furthermore, they showed 89.4\% recovery rate of moderate acute malnutrition and $86.5 \%$ recovery rate of severe acute malnutrition, while only $2.8 \%$ case fatality rate for moderate acute malnutrition and $4.2 \%$ for severe acute malnutrition in the intervention arm compared to $7 \%$ default case fatality rate in the community. However, handover conditions and scaling-up requirements were unsatisfactory because of the poor integration of evaluated package of intervention into health system, lack of resources and insufficient advocacy and supervision which led to poor implementation nationwide. However, Durlak \& DuPre (12) showed how better outcomes of the intervention are achievable when implemented widely. Our study revealed that the level of implementation, especially effective implementation of MSG intervention was very low with no substantial change in feeding practices as well as related behavioural factors even six years after its implementation, which has in turn resulted in no substantial change of the prevalence of underweight, wasting and stunting among underfive children over the years in the community.

A number of issues need to be considered in interpreting data in this study. First, this study was a descriptive cross-sectional study in which data on some variables were collected by recall. Therefore, recall bias as well as misclassification bias are possible in our study. Second, this study was conducted in Monaragala District only and the findings may not be reflective of the level of implementation of MSG intervention in other districts in the country. However, findings of this study are consistent with a formative review of MSG intervention which was conducted in Northern and Eastern Provinces of Sri Lanka in 2015 (7), suggesting that our findings could be generalised to other districts as well.

\section{Conclusions \& Recommendations}

Population coverage of MSG intervention was significantly low and not uniformly implemented in the community. Present level of implementation of MSG intervention was not effective enough to make a significant improvement in feeding practices and behaviour related to nutrition and growth promotion among under-five children. The MSG intervention should be revisited, and appropriate measures taken for its successful further implementation in the community.

\section{Public Health Implications}

Scientific evaluation of public health interventions is important as far as the outcome and impact of such interventions are concerned. This study found improvement in only a few feeding practices among children of intervention category. Under-five under nutrition is still a public health problem in Sri Lanka with less progress over the last two decades. Implementing community-based public health interventions based on strong scientific evidence and with close monitoring and evaluation mechanisms is required to further improve under-five nutritional status in Sri Lanka.

\section{Author Declarations}

Competing interests: Authors declare that they do not have competing interests.

Ethics approval and consent to participate: Ethical clearance for this study was granted by Ethics Review Committee of the Faculty of Medicine, University of Peradeniya (ERC No: 2017/EC/87). Written approval for implementing the study was obtained from Provincial Ministry of Health, Indigenous Medicine, Probation and Childcare, Womens Affairs and Social Welfare. Informed written consent was taken from study participants before data collection.

Funding: Authors acknowledge the provincial authorities for providing funds for this study. 
Acknowledgements: Authors acknowledge the Provincial Ministry of Health for granting approval to implement this study and Provincial as well as Monaragala Regional Health Directorates and MOHs with their staff for the immense support for successful completion of this research project in the district of Monaragala.

Author contributions: NG conceived the study, analysed data and wrote the initial version of the manuscript. EM and NW supervised all aspects of the study including designing, data analysis and manuscript writing.

\section{References}

1. Black RE, Victoria CG, Walker SP, Bhutta ZA, Christian P, Onis MD, Ezzati M, McGregor SG, Katz J, Martorell R, Uauy R. Maternal and child undernutrition and overweight in low-income and middle-income countries. Lancet 2013; 382: 427-451.

2. United Nations Children's Fund, World Health Organization \& The World Bank. UNICEF-WHOWorld Bank Joint Child Malnutrition Estimates. New York: UNICEF; Geneva: WHO; Washington: World Bank, 2012. Available from: http://www.who.int/ nutgrowthdb/jme_unicef_who_wb.pdf.

3. Department of Census and Statistics (DCS). Demographic and Health Survey Report of year 2006/7. Colombo: Ministry of Healthcare and Nutrition, 2007.

4. Hien NN \& Kam S. Nutritional status and the characteristics related to malnutrition in children under five years of age in Nghean, Vietnam. Journal of
Preventive Medicine and Public Health 2008; 41(4): 232-240.

5. Black RE, Allen LH, Bhutta ZA, Caulfield LE, de Onis M, Ezzati M, et al. Maternal and child undernutrition: global and regional exposures and health consequences. Lancet 2008; 371(9608): 243-260.

6. Somassé YE, Bahwere P, Laokri S, Elmoussaoui N, Donnen P. Sustainability and scaling-up analysis of community-based management of acute malnutrition: lessons learned from Burkina Faso. Food and Nutrition Bulletin 2013; 34(3): 338-348.

7. Malekafzali H, Abdollahi Z, Mafi A, Naghavi M. Community-based nutritional intervention for reducing malnutrition among children under 5 years of age in the Islamic Republic of Iran. Eastern Mediterranean Health Journal 2000; 6(2-3): 238-245.

8. Tillekeratne V, Seneviratne J, Delabandara R. Review of the functioning and impact of Mother Supportive Groups. Ministry of Health and UNICEF Sri Lanka, 2015.

9. Department of Census and Statistics (DCS). Census of Population and Housing 2012. Colombo, Ministry of Health, 2012.

10. Department of Health Services. Annual Health Bulletin 2018. Uva Province: Ministry of Health, 2012.

11. Hulley SB et al. Designing clinical research: an epidemiological approach. New York: Williams and Wilkins, 1988.

12. Durlak JA, DuPre EP. Implementation matters: a review of research on the influence of implementation on program outcomes and the factors affecting implementation. American Journal of Community Psychology 2008; 41: 327-350. 